\title{
Metabolic Handling of Orally Administered Glucose in Cirrhosis
}

\author{
Yolanta T. Kruszynska, Alexander Meyer-Alber, Froogh Darakhshan, Philip D. Home, ${ }^{*}$ and Neil Mclntyre \\ University Department of Medicine, Royal Free Hospital School of Medicine, London NW3 2QG, United Kingdom; and *Department of \\ Medicine, University of Newcastle-upon-Tyne, Newcastle-upon-Tyne NE2 4HH, United Kingdom
}

\begin{abstract}
We used a dual-isotope method (oral $\left[1-{ }^{14} \mathrm{C}\right]$ glucose and intravenous $\left[6-{ }^{3} \mathrm{H}\right]$ glucose) to examine whether the oral glucose intolerance of cirrhosis is due to $(a)$ a greater input of glucose into the systemic circulation (owing to a lower first-pass hepatic uptake of ingested glucose, or to impaired inhibition of hepatic glucose output ), (b) a lower rate of glucose removal, or (c) a combination of these mechanisms. Indirect calorimetry was used to measure oxidative and nonoxidative metabolism. Basal plasma glucose levels ( cirrhotics, 5.6 $\pm 0.4[\mathrm{SE}]$, controls, $5.1 \pm 0.2 \mathrm{mmol} /$ liter), and rates of glucose appearance (Ra) and disappearance ( $R d$ ) were similar in the two groups. After $75 \mathrm{~g}$ of oral glucose, plasma glucose levels were higher in cirrhotics than controls, the curves diverging for 80 min despite markedly higher insulin levels in cirrhotics. During the first 20 min, there was very little change in glucose $R d$ and the greater initial increase in plasma glucose in cirrhotics resulted from a higher Ra of ingested $\left[1-{ }^{14} \mathrm{C}\right]$ glucose into the systemic circulation, suggesting a reduced first-pass hepatic uptake of portal venous glucose. The continuing divergence of the plasma glucose curves was due to a lower glucose Rd between 30 and 80 min (cirrhotics $236 \pm 17 \mathrm{mg} / \mathrm{kg}$ in $50 \mathrm{~min}$, controls $280 \pm 17$ $\mathrm{mg} / \mathrm{kg}$ in $50 \mathrm{~min}, P<0.05$, one-tailed test). Glucose metabolic clearance rate rose more slowly in cirrhotics and was significantly lower than in controls during the first $\mathbf{2}$ h after glucose ingestion $(2.24 \pm 0.17$ vs. $3.30 \pm 0.23 \mathrm{ml} / \mathrm{kg}$ per $\mathrm{min}, P$ $<0.005)$, in keeping with their known insulin insensitivity. Despite the higher initial glucose $\mathbf{R a}$ in cirrhotics, during the entire 4-h period the quantity of total glucose and of ingested glucose (cirrhotics $54 \pm 2 \mathrm{~g}$ [ $72 \%$ of oral load], controls $54 \pm 3 \mathrm{~g}$ ) appearing in the systemic circulation were similar. Overall glucose Rd (cirrhotics $72.5 \pm 3.8 \mathrm{~g} / 4 \mathrm{~h}$, controls $77.2 \pm 2.2 \mathrm{~g} / 4 \mathrm{~h}$ ) and percent suppression of hepatic glucose output over $4 \mathrm{~h}$ (cirrhotics, $53 \pm 10 \%$, controls $49 \pm 8 \%$ ) were also similar.

After glucose ingestion much of the extra glucose utilized was oxidized to provide energy that in the basal state was derived from lipid fuels. Glucose oxidation after glucose ingestion was similar in both groups and accounted for approximately two-thirds of glucose $R d$. The reduction in overall nonoxidative glucose disposal did not reach significance ( $21 \pm 5$ vs. $29 \pm 3 \mathrm{~g} / 4$ h, $0.05<P<0.1$ ). Although our data would be compatible
\end{abstract}

Address reprint requests to Dr. Yolanta T. Kruszynska, University Department of Medicine, Royal Free Hospital, Pond Street, London NW3 2QG.

Received for publication 3 October 1991 and in revised form 4 August 1992.

J. Clin. Invest.

(c) The American Society for Clinical Investigation, Inc.

0021-9738/93/03/1057/10 \$2.00

Volume 91, March 1993, 1057-1066 with an impairment of tissue glycogen deposition after oral glucose, glucose storage as glycogen probably plays a small part in overall glucose disposal.

Our results suggest that the higher glucose levels seen in cirrhotics after oral glucose are due initially to an increase in the amount of ingested glucose appearing in the systemic circulation, and subsequently to an impairment in glucose uptake by tissues due to insulin insensitivity. Impaired suppression of hepatic glucose output does not contribute to oral glucose intolerance. (J. Clin. Invest. 1993. 91:1057-1066.) Key words: glucose intolerance $\bullet$ glucose kinetics $\bullet$ insulin resistance

\section{Introduction}

Most patients with cirrhosis have impaired tolerance to oral glucose $(1,2)$, even though they have a greater insulin response, and overt diabetes is two to four times more prevalent than in the general population (3). For many years this impaired tolerance was attributed to reduced first-pass hepatic extraction of ingested glucose (due to portal systemic shunting and/or hepatocellular dysfunction), as it was believed that the normal liver removes most of the absorbed glucose during its first passage through the portal circulation. This explained a paradox, namely that cirrhotics have impaired oral glucose tolerance but either no intolerance, or a much lesser degree of intolerance, to glucose given intravenously as a bolus $(1,2)$. However, first-pass hepatic uptake of glucose is now considered to be relatively unimportant in quantitative terms (4). In dogs arterial blood glucose levels were similar when glucose was infused either into the portal vein or into a systemic vein (5), and in animal and human studies portacaval shunting appears to have little or no effect on oral glucose tolerance (6-9).

It is now well recognized, contrary to earlier studies (10), that peripheral tissues account for most of the uptake of ingested glucose $(11,12)$. Several studies using the hyperinsulinemic euglycemic clamp technique have documented marked peripheral tissue insulin insensitivity in cirrhosis (13-16). Because the rate of glucose uptake by peripheral tissues depends both on their sensitivity to insulin and on the magnitude of the insulin response, both peripheral tissue insulin insensitivity and an impairment of insulin secretion in cirrhosis could explain the oral glucose intolerance (13).

Another factor that might affect blood glucose levels after oral glucose is the degree of suppression of hepatic glucose output. If in cirrhotics the liver, like peripheral tissues, is insensitive to the action of insulin, one might expect that after glucose ingestion the rate of hepatic glucose production, and hence the total amount of glucose entering the systemic circulation, would be higher than in normal subjects. However, basal hepatic glucose production is normal $(15,17)$ or decreased $(18)$ in cirrhotics with normal fasting glucose levels, and studies using the euglycemic clamp have suggested a normal suppres- 
sion of hepatic glucose output ( $\mathrm{HGO})^{1}$ in response to physiological increases in plasma insulin concentration $(15,19)$.

There have been no studies on the dynamics of the handling of ingested glucose in cirrhosis. Leatherdale et al. (20) found normal forearm glucose uptake after oral glucose in cirrhotics, albeit at higher plasma glucose and insulin levels than in controls. To account for the higher plasma glucose levels, they suggested that systemic delivery of glucose must be increased in cirrhosis but they did not measure the systemic appearance rates of either total or ingested glucose. In the present study on cirrhotics and controls given an oral glucose load we used a dual-isotope technique, with infusion of $\left[{ }^{3} \mathrm{H}\right]$ glucose intravenously and ingestion of $\left[{ }^{14} \mathrm{C}\right]$ glucose $(12,21,22)$, to test the following hypotheses: $(a)$ there would be no difference in the amount of oral glucose appearing in the systemic circulation (i.e., in the amount of glucose escaping first-pass hepatic uptake); $(b)$ there would be no difference in the effect of oral glucose on HGO; $(c)$ the total systemic appearance rate of glucose would be similar, but the rate of glucose disappearance from plasma would be decreased in cirrhosis. As studies employing the euglycemic clamp technique have shown impairment of stimulation of muscle glycogen deposition by insulin (14), but normal stimulation of oxidative glucose metabolism (19), we also employed indirect calorimetry to ascertain whether the pattern of glucose metabolism after glucose ingestion is altered in cirrhosis with more of the glucose taken up by tissues being immediately oxidised.

\section{Methods}

Subjects. Eight patients with stable biopsy-proven alcoholic cirrhosis and eight normal control subjects were studied. The study was approved by the local ethical committee. The clinical characteristics of the patients and controls are given in Table I. Subjects with overt diabetes (fasting blood glucose $>6.6 \mathrm{mmol} /$ liter) or a family history of diabetes mellitus were excluded. None were on treatment known to affect glucose tolerance. Three patients were taking spironolactone but none had ascites at the time of study. Five patients had oesophageal varices on endoscopy; three of these had previously bled from varices. One patient had suffered from hepatorenal syndrome 6 mo previously but had normal renal function at the time of study. The patients had abstained from alcohol for at least 1 mo before study. All were in good nutritional state and consumed a diet containing at least $200 \mathrm{~g}$ of carbohydrate per day.

Protocol. Studies were performed in the morning after an overnight fast. For blood sampling, a venous cannula was inserted retrogradely in a hand vein, the hand being maintained in a hand warmer at $65^{\circ} \mathrm{C}$. After each blood sample, the cannula was flushed with $0.15 \mathrm{~mol} /$ liter $\mathrm{NaCl}$ in water. A second cannula was inserted in a vein in the antecubital fossa for infusion of glucose tracer. At $0800 \mathrm{~h}$, a primed $(30 \mu \mathrm{Ci})$, continuous infusion of $\left[6-{ }^{3} \mathrm{H}\right]$ glucose $(0.4 \mu \mathrm{Ci} / \mathrm{min})$ (Amersham International, Amersham, UK) was begun and continued for $6 \mathrm{~h}$. Four basal blood samples were taken between $105 \min (t=-15 \mathrm{~min})$ and $120 \mathrm{~min}(t=0 \mathrm{~min})$ after the start of the infusion of the $\left[6-{ }^{3} \mathrm{H}\right]$ glucose, for measurement of plasma glucose concentration and specific activity, and of serum insulin, nonesterified fatty acids (NEFA) and blood intermediary metabolite concentrations. Subjects then $(t=0 \mathrm{~min})$ ingested $75 \mathrm{~g}$ of glucose (containing $100 \mu \mathrm{Ci}\left[1-{ }^{14} \mathrm{C}\right]$ glucose) in $390 \mathrm{ml}$ of water. The glucose was divided into five aliquots and given at minute

1. Abbreviations used in this paper: HGO, hepatic glucose output; MCR, metabolic clearance rate; NEFA, non-esterified fatty acids; $\mathbf{R a}$, rate of appearance; $\mathrm{RaO}$, rate of appearance of ingested glucose; $\mathrm{Rd}$, rate of disappearance.
Table I. Clinical Characteristics of the Subjects Studied

\begin{tabular}{lcc}
\hline & Controls & Cirrhotics \\
\hline$n$ & 8 & 8 \\
Age & $49 \pm 13$ & $54 \pm 11$ \\
Weight $(\mathrm{kg})$ & $73 \pm 12$ & $71 \pm 11$ \\
BMI $\left(\mathrm{kg} / \mathrm{m}^{2}\right)$ & $24.2 \pm 3.2$ & $25.6 \pm 2.7$ \\
Albumin $(\mathrm{g} / \mathrm{liter})$ & $43 \pm 3$ & $36 \pm 4$ \\
Bilirubin $(\mu \mathrm{mol} / \mathrm{liter})$ & $12 \pm 5$ & $20 \pm 7$ \\
Prothrombin time $(s)$ & $13 \pm 1$ & $17 \pm 1$ \\
\hline
\end{tabular}

\section{Mean \pm SD.}

intervals. Blood samples for glucose concentration and specific activity were taken every 10 min until +150 min and then every 15 min until $+240 \mathrm{~min}$. Blood samples for serum insulin were taken every $5 \mathrm{~min}$ from 0 to $+60 \mathrm{~min}$, every $10 \mathrm{~min}$ until $+150 \mathrm{~min}$, and then every 15 min until $+240 \mathrm{~min}$. Blood samples for NEFA and intermediary metabolites were taken at 15-30-min intervals throughout the study.

Whole-body glucose and lipid oxidation. Substrate oxidation rates in the basal state and after the oral glucose load were determined by indirect calorimetry (Deltatrac Metabolic Monitor, Datex Instruments, Helsinki, Finland). Briefly, a clear plastic ventilated hood was placed over the subjects head and room air was drawn through the hood at a constant rate of $40 \mathrm{liter} / \mathrm{min}$. Oxygen consumption (paramagnetic $\mathrm{O}_{2}$ sensor) and $\mathrm{CO}_{2}$ production (infrared $\mathrm{CO}_{2}$ sensor) were measured for $15 \mathrm{~min}$ during each $30 \mathrm{~min}$ of the study, and the means of the values during the last $10 \mathrm{~min}$ of the measurement interval were used for calculations. The machine was calibrated before each study and at intervals throughout the experiment. A 2-h basal urine sample was obtained and a further sample was obtained at the conclusion of the study for determination of basal and post-glucose urinary nitrogen excretion rates. Nonprotein respiratory quotient was calculated from the rates of oxygen consumption, carbon dioxide production, and urinary nitrogen excretion $(23,24)$. Carbohydrate and lipid oxidation and energy expenditure were calculated from standard equations (23, 24). In four cirrhotic patients negative rates of lipid oxidation were observed after the oral glucose load. These negative values are thought to be numerically equivalent to the net amount of lipid synthesized $(23,25)$.

The stoichiometry of lipid synthesis from glucose is given by the following equation: $1 \mathrm{~g}$ of glucose +0.045 liter of $\mathrm{O}_{2} \rightarrow 0.35 \mathrm{~g}$ of fat +0.25 liter of $\mathrm{CO}_{2}$. The respiratory quotient $(\mathrm{RQ})$ for lipid synthesis from glucose is 5.6. Under conditions of net lipogenesis, the standard equation (glucose oxidized $=4.55 \mathrm{VCO}_{2}-3.21 \mathrm{VO}_{2}-2.87 \mathrm{~N}$ ) will give an overestimate of the amount of glucose oxidized $(23,25)$ by an amount equal to that converted to fat. Therefore, when negative rates of lipid oxidation were obtained (in the four patients) glucose oxidation was calculated from the following equation (23): glucose oxidized $=1.34\left(1.00 \mathrm{VCO}_{2}-4.88 \mathrm{~N}\right)$. Energy expenditure in the basal period ( $\mathrm{kcal} / \mathrm{min}$ ) was subtracted from the mean energy expenditure during the 4-h post oral glucose period to determine the thermogenic response to the load. Total nonoxidative glucose disposal during the $4 \mathrm{~h}$ after the oral glucose load was calculated by subtracting the amount of glucose oxidized and the glucose excreted in the urine from total plasma glucose disappearance rate $(\mathrm{Rd})$.

Analytical procedures. Plasma glucose was determined by a glucose oxidase method (Yellow Springs Instruments glucose analyser, Clandon Scientific, London, UK). For determination of $\left[{ }^{3} \mathrm{H}\right]-$ and $\left[{ }^{14} \mathrm{C}\right]-$ glucose specific activity, $1 \mathrm{ml}$ of plasma was deproteinized with $\mathrm{Ba}(\mathrm{OH})_{2} / \mathrm{ZnSO}_{4}(26)$ and the neutral supernatant after centrifugation was passed through anion exchange columns (AG2X8, Sigma Chemical Co., Poole, Dorset, UK). The eluate was evaporated to remove tritiated $\mathrm{H}_{2} \mathrm{O}$ and then reconstituted in $2 \mathrm{ml}$ of water. To $1 \mathrm{ml}$ of this reconstituted eluate $10 \mathrm{ml}$ of scintillation fluid (Cocktail T, British Drug Houses, Poole, UK) was added, and ${ }^{3} \mathrm{H}$ and ${ }^{14} \mathrm{C}$ disintegrations 
per minute ( $\mathrm{dpm})$ were determined by dual-channel scintillation spectrometry in a model PW4700 liquid scintillation counter (NV Philips' Gloeilampen-fabrieken, Lelyweg, Holland) using an external standard to correct for efficiency and overlapping. The remainder of the reconstituted column eluate was taken for determination of the amount of recycled ${ }^{14} \mathrm{C}$ by determining ${ }^{14} \mathrm{C}$ in the sixth position using periodate degradation and subsequent trapping of the sixth carbon with dimedone (27). The ${ }^{14} \mathrm{C} \mathrm{dpm}$ in the sixth carbon were corrected for the efficiency of periodate degradation and recovery by simultaneous determination of ${ }^{3} \mathrm{H} \mathrm{dpm}$ on the sixth carbon. The $6-{ }^{14} \mathrm{C}$ dpm were multiplied by 4 and subtracted from total ${ }^{14} \mathrm{C}$ dpm to give plasma $\left[1-{ }^{14} \mathrm{C}\right]-$ glucose dpm (28). Quadruplicate aliquots of the labeled glucose infusate and the oral $\left[1-{ }^{14} \mathrm{C}\right]$ glucose were added to nonradioactive plasma and processed in parallel with the plasma samples to allow calculation of the $\left[6-{ }^{3} \mathrm{H}\right]$ glucose infusion rate and specific activity of the ingested glucose.

Serum insulin was measured by a double-antibody technique (29). The intra- and interassay coefficients of variation were $6.8 \%$ and $7.9 \%$, respectively. Serum NEFA were determined using an acyl-CoA oxidase-based colorimetric kit (Wako NEFA-C; Wako Chemicals, Neuss, FRG). Blood for estimation of intermediary metabolites was deproteinized with perchloric acid $(0.6 \mathrm{~mol} /$ liter $)$ and the extract was assayed for lactate and pyruvate by enzymic fluorimetric methods (30) in a model LS50 luminescence spectrometer (Perkin-Elmer, Beaconsfield, UK). Urinary nitrogen was measured by the method of Kjeldahl (31).

Calculations. The rates of total glucose appearance ( $\mathrm{Ra}$ ) and disappearance $(\mathrm{Rd})$ were calculated from the $\left[6-{ }^{3} \mathrm{H}\right]$ glucose data using the non-steady-state equations of Steele et al. (32). A distribution volume of 0.19 liter $/ \mathrm{kg}$ and a pool fraction of 0.5 were used in the calculation (33). The rate of appearance of ingested glucose in the systemic circulation $(\mathrm{RaO})$ was calculated from the $\left[1-{ }^{14} \mathrm{C}\right]$ glucose data, after correction for recycling, using the equation of Chiasson et al. (34). This represents a modification of the Steele equation; $1-{ }^{14} \mathrm{C} \mathrm{dpm} / \mathrm{ml}$ is substituted for the concentration of unlabeled glucose so that the $\left[6-{ }^{3} \mathrm{H}\right]-$ glucose traces the appearance of the $\left[1-{ }^{14} \mathrm{C}\right]$ glucose instead of unlabeled glucose. HGO was calculated as the difference between total glucose $\mathrm{Ra}$ and the rate of appearance of the ingested $\left[1-{ }^{14} \mathrm{C}\right]$ glucose. Splanchnic glucose uptake was calculated as the difference between the amount of oral glucose given and the total systemic appearance of the oral glucose, assuming complete absorption of the oral glucose load within the $4 \mathrm{~h}$ of the study.

Statistical analysis. Results are expressed as mean \pm SEM unless otherwise indicated. The areas under the glucose appearance, disappearance, and oxidation curves were calculated using the trapezoidal rule. Correlations were sought by Pearson's least squares method. The significance of differences was tested by Student's paired or unpaired $t$ test as appropriate. A one-tailed test $(1 P)$ was used to test the hypothesis that $R d$ was lower in cirrhotics ( 35$)$. A $P$ value of $<0.05$ was considered statistically significant.

\section{Results}

Plasma glucose and serum insulin concentrations. Fasting plasma glucose concentrations tended to be a little higher in the cirrhotics $(5.6 \pm 0.4 \mathrm{mmol} /$ liter $)$ than in controls $(5.1 \pm 0.2$ $\mathrm{mmol} /$ liter $)$, but this difference did not reach significance. The plasma glucose increased after oral glucose; the peak in both groups was at $60 \mathrm{~min}$. The glucose concentration was signifcantly higher in cirrhotics than in controls from +20 min until +150 min (Fig. 1). The two curves diverged from the beginning and continued to diverge even after their peaks were reached, the maximum difference between them occurring at $80 \mathrm{~min}$.

Fasting serum insulin concentrations were six times higher in the cirrhotic patients $(47.0 \pm 12.5$ vs. $8.3 \pm 2.9 \mathrm{mU} /$ liter, $P$
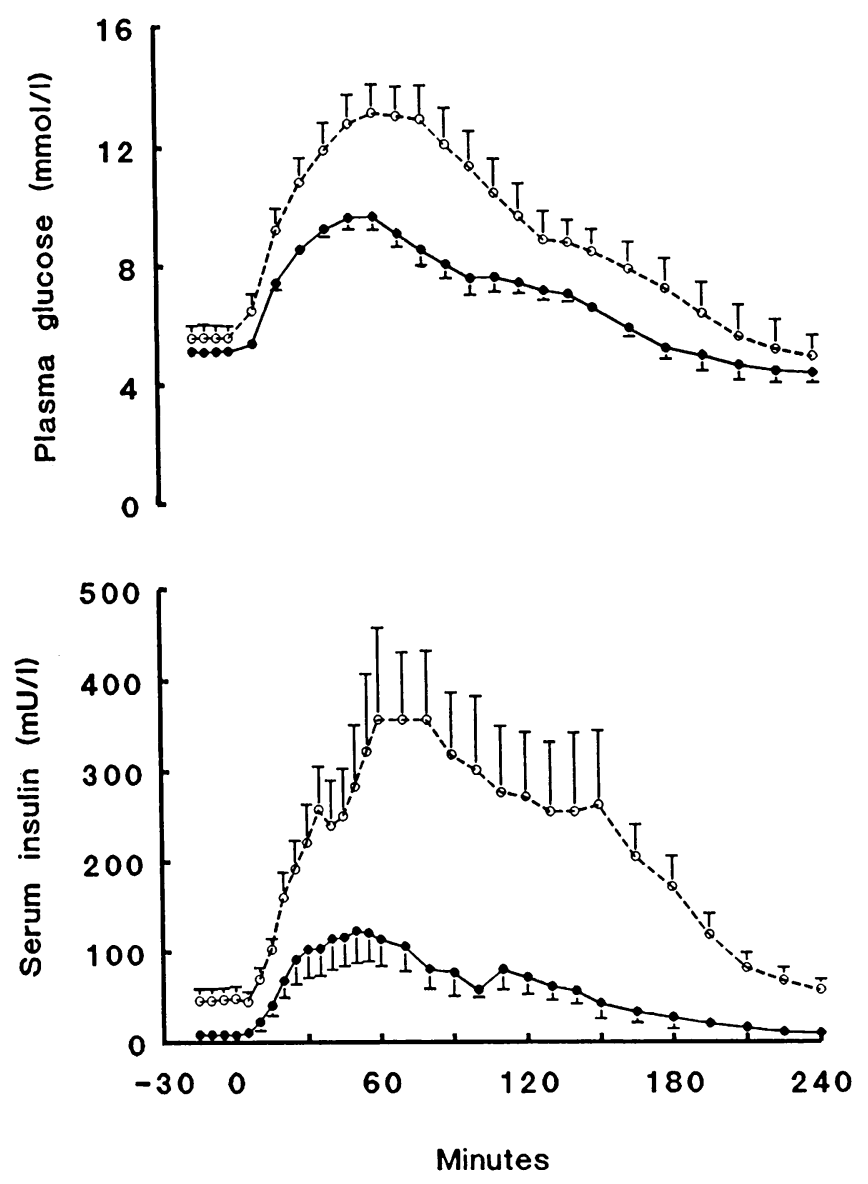

Figure 1. Plasma glucose and serum insulin concentrations in eight cirrhotics $(\circ)$ and eight controls $(\bullet)$ after an overnight fast and after ingestion of $75 \mathrm{~g}$ of glucose at $t=0 \mathrm{~min}$. Mean \pm SEM.

$<0.001)$. After glucose ingestion, serum insulin levels were much higher in the cirrhotics and they remained elevated until +240 min (Fig. 1).

Appearance rates of total, hepatic, and ingested glucose. The $\left[{ }^{3} \mathrm{H}\right]$ glucose specific activity before glucose ingestion was not significantly different in cirrhotics $(1,210 \pm 144 \mathrm{dpm} /$ $\mu \mathrm{mol}$ ) and controls ( $980 \pm 45 \mathrm{dpm} / \mu \mathrm{mol}$ ) (Fig. 2 ) nor were the calculated rates of glucose appearance in the basal state (cirrhotics $2.1 \pm 0.2 \mathrm{mg} / \mathrm{kg}$ per min, controls $2.4 \pm 0.1 \mathrm{mg} / \mathrm{kg}$ per min, NS). After glucose ingestion, $\left[{ }^{3} \mathrm{H}\right]$ glucose specific activity fell rapidly in both groups; between 80 and 130 min there was a gradual increase in ${ }^{3} \mathrm{H}$ specific activity in the cirrhotics, suggesting a fall in total $\mathrm{Ra}$; after +165 min there was a similar increase in ${ }^{3} \mathrm{H}$ specific activity in both groups (Fig. 2). After glucose ingestion total glucose $\mathrm{Ra}$ in the controls rose sharply to a plateau from 15 to $55 \mathrm{~min}$ (being $6.0 \pm 0.3 \mathrm{mg} / \mathrm{kg}$ per min at $35 \mathrm{~min}$ ); it then fell gradually until $95 \mathrm{~min}$, and more rapidly from $135 \mathrm{~min}$ to levels not significantly different from basal at $210 \mathrm{~min}$. In the cirrhotics there was a sharp initial peak at 15 min when the total $\mathrm{Ra}$ was higher than in controls $(P<0.05)$; during the first $20 \mathrm{~min}$ the integrated total glucose $\mathrm{Ra}$ was significantly greater in cirrhotics $(105.0 \pm 7.8 \mathrm{mg} / \mathrm{kg}$ in $20 \mathrm{~min})$ than in controls $(85.4 \pm 4.8 \mathrm{mg} / \mathrm{kg}$ in $20 \mathrm{~min})(P<0.05)$. After the initial peak the total $\mathrm{Ra}$ fell more sharply in cirrhotics than in controls, and this decline was sustained for longer (Fig. 3), so that, from 80 to $130 \mathrm{~min}$ when the glucose curves were 

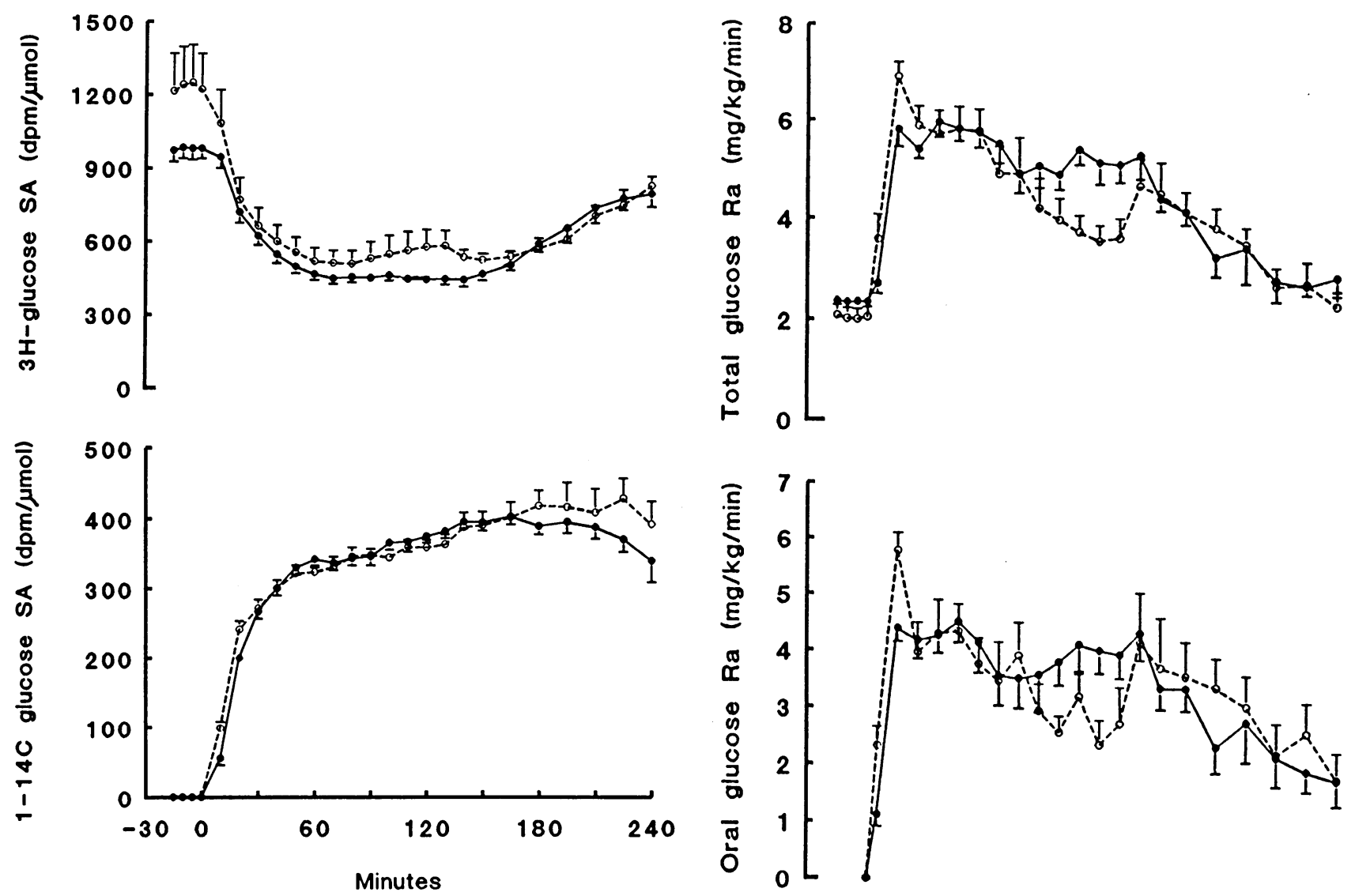

Figure 2. Plasma $\left[{ }^{3} \mathrm{H}\right]$ glucose and $\left[1-{ }^{14} \mathrm{C}\right]$ glucose specific activities $(\mathrm{SA})$ in eight cirrhotics $(\mathrm{O})$ and eight controls $(\bullet)$ before and after ingestion of $75 \mathrm{~g}\left[1-{ }^{14} \mathrm{C}\right]$ glucose. Mean \pm SEM.

converging, the integrated 50-min total $\mathrm{Ra}$ was lower in cirrhotics $(191.5 \pm 14.5 \mathrm{mg} / \mathrm{kg}$ in $50 \mathrm{~min})$ than in controls $(250.3 \pm 18.1 \mathrm{mg} / \mathrm{kg}$ in $50 \mathrm{~min})(P<0.05)$. There was a secondary rise in total $\mathrm{Ra}$ in cirrhotics, coinciding with a shoulder in the plasma glucose curve between 130 and 140 min (Fig. 1). The total integrated glucose appearance was not significantly different in the two groups ( cirrhotics $71.6 \pm 3.3 \mathrm{~g} / 4 \mathrm{~h}$, controls $76.1 \pm 1.8 \mathrm{~g} / 4 \mathrm{~h}, \mathrm{NS}$ ).

There was a sharp initial increase in plasma $\left[1-{ }^{14} \mathrm{C}\right]$ glucose specific activity in both groups, which was followed by a more gradual rise (Fig. 2). In the controls the peak $\left[1-{ }^{14} \mathrm{C}\right]$ glucose specific activity at $165 \mathrm{~min}$ was $404 \pm 11 \mathrm{dpm} / \mu \mathrm{mol}$, which was $77 \pm 2 \%$ of the specific activity of the ingested glucose; in cirrhotics the peak, reached at $225 \mathrm{~min}$, was $429 \pm 28 \mathrm{dpm} / \mu \mathrm{mol}$, which was $81 \pm 5 \%$ of that of the ingested glucose. In both groups the early increase in total $\mathrm{Ra}$ was entirely due to the increase in $\mathrm{Ra}$ of ingested $\left[1-{ }^{14} \mathrm{C}\right]$ glucose $(\mathrm{RaO})$. In the cirrhotics $\mathrm{RaO}$ showed a biphasic pattern similar to that seen for total glucose Ra (Fig. 3). There was a peak at $15 \mathrm{~min}$ ( 10-20min period), and a significant difference in the 20 -min integrated $\mathrm{RaO}$ (cirrhotics $81.1 \pm 6.2 \mathrm{mg} / \mathrm{kg}$ in $20 \mathrm{~min}$, controls $55.2 \pm 1.8 \mathrm{mg} / \mathrm{kg}$ in $20 \mathrm{~min} ; P<0.002$ ). However, the overall systemic appearance of ingested glucose during the $4 \mathrm{~h}$ after oral glucose was identical in the cirrhotics $(53.8 \pm 2.4 \mathrm{~g}$ [ $72 \%$ of the oral glucose load]) and controls $(54.2 \pm 2.7 \mathrm{~g}[72 \%])$. Assuming complete absorption of the glucose load, initial splanchnic retention of the glucose load was $21.2 \pm 2.4 \mathrm{~g}$ in cirrhotics and $20.9 \pm 2.7 \mathrm{~g}$ in the controls.

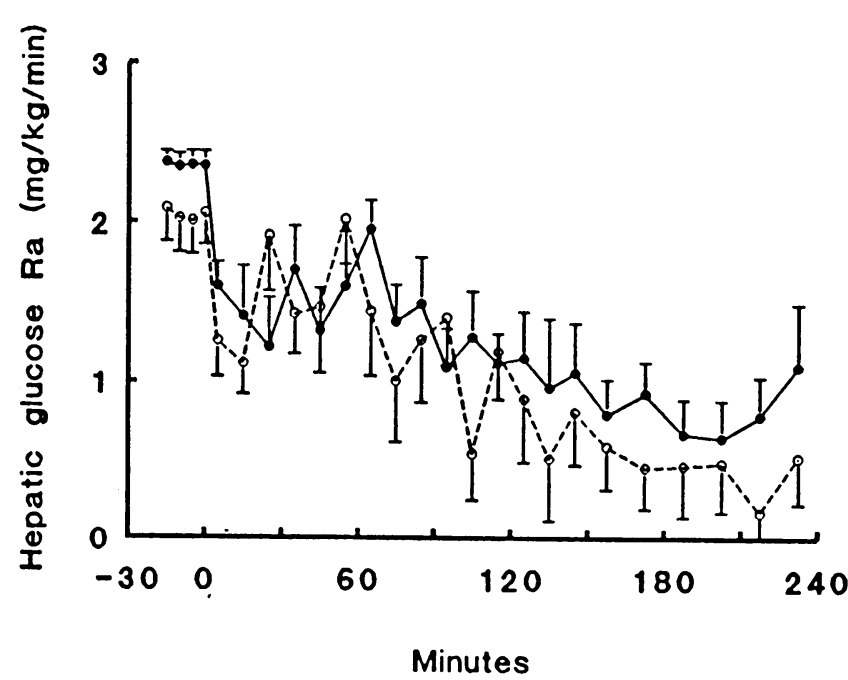

Figure 3. Rates of total glucose appearance, oral glucose appearance, and hepatic glucose appearance in eight cirrhotics $(0)$ and eight controls $(\bullet)$ after ingestion of a load of $75 \mathrm{~g}$ glucose at $t=0 \mathrm{~min}$. The data have been plotted at the midpoint of each measurement interval. Mean \pm SEM. $R a$, rate of appearance.

In both groups the systemic appearance of recycled $\left[{ }^{14} \mathrm{C}\right]-$ glucose paralleled that of the oral $\left[1-{ }^{14} \mathrm{C}\right]$ glucose, and at no time did it exceed $10 \%$ of total ${ }^{14} \mathrm{C}$ counts. The proportion of total glucose $\mathrm{Ra}$ accounted for by recycled glucose was not different between cirrhotics and controls.

After oral glucose there were similar changes in calculated HGO in both groups. Initially there was a very rapid and marked reduction in HGO, which was followed by a more gradual decline over the next $3 \mathrm{~h}$ (Fig. 3), so that during the 4th 
$\mathrm{h}$ after oral glucose it was only $18 \pm 10 \%$ of basal values in the cirrhotics and $34 \pm 8 \%$ of that in the basal state in the controls. The extent of HGO suppression, averaged over the $4 \mathrm{~h}$ period, was similar in the cirrhotics $(53.0 \pm 10.2 \%)$ and controls $(48.8 \pm 7.7 \%$ ) (Fig. 3). Overall HGO during the $4 \mathrm{~h}$ after glucose ingestion was also similar in cirrhotics $(17.8 \pm 4.8 \mathrm{~g} / 4 \mathrm{~h})$ and controls $(21.9 \pm 3.9 \mathrm{~g} / 4 \mathrm{~h})$.

Rates of glucose disappearance. Because the fasting glucose levels did not change, the glucose disappearance rate $(R d)$ in the basal state was the same as the $\mathrm{Ra}$ in both groups (cirrhotics $2.1 \pm 0.2 \mathrm{mg} / \mathrm{kg}$ per min; controls $2.4 \pm 0.1 \mathrm{mg} / \mathrm{kg}$ per min; NS). Basal glucose metabolic clearance rate (MCR) was significantly lower in cirrhotics ( $1.92 \pm 0.15$ vs. $2.56 \pm 0.08 \mathrm{ml} / \mathrm{kg}$ per min: $P<0.005)$. The overall $\mathrm{Rd}$ after glucose ingestion was similar in cirrhotics $(1,022 \pm 31 \mathrm{mg} / \mathrm{kg}$ in $4 \mathrm{~h})$ and controls $(1,074 \pm 46 \mathrm{mg} / \mathrm{kg}$ in $4 \mathrm{~h})$, and represented the removal of $72.5 \pm 3.8$ and $77.2 \pm 2.2 \mathrm{~g}$ of glucose, respectively, during the 4-h period (Fig. 4). However, there was little or no change in $\mathrm{Rd}$ in either group during the first $20 \mathrm{~min}$, and reduction in $\mathrm{Rd}$ could have accounted neither for the rapid increase in plasma glucose in both groups, nor for the divergence in the plasma glucose curves during this period. Glucose Rd then rose more slowly in cirrhotics (Fig. 4) and between 30 and 80 min the
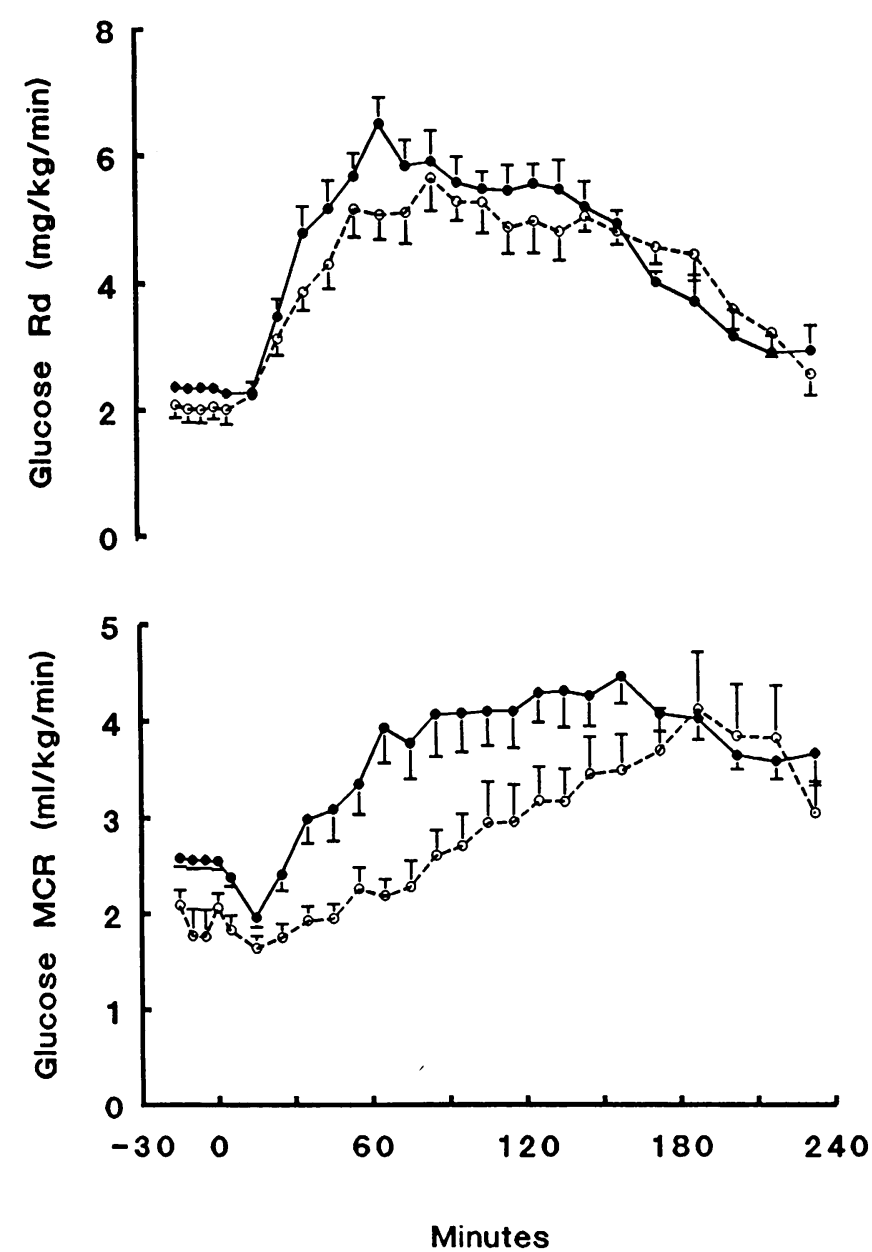

Figure 4. Rates of glucose disappearance and glucose metabolic clearance (MCR) in eight cirrhotics $(0)$ and eight normal controls (•) after a load of $75 \mathrm{~g}$ oral glucose at $t=0 \mathrm{~min}$. The data have been plotted at the midpoint of each measurement interval. Mean \pm SEM. $\mathrm{Rd}$, rate of disappearance. integrated $\mathrm{Rd}$ was significantly lower than in controls $(236 \pm 17$ $\mathrm{mg} / \mathrm{kg}$ in $50 \mathrm{~min}$ vs. $280 \pm 17 \mathrm{mg} / \mathrm{kg}$ in $50 \mathrm{~min}, 1 P<0.05$ ).

After glucose ingestion cirrhotics had a markedly delayed rise in glucose MCR (Fig. 4). Whereas glucose MCR rose in controls to about $4 \mathrm{ml} / \mathrm{kg}$ per min by $60 \mathrm{~min}$ and remained around this level until $+180 \mathrm{~min}$, cirrhotics did not reach their maximum rate of glucose clearance until $+195 \mathrm{~min}$. During the first $2 \mathrm{~h}$ after glucose ingestion the mean glucose MCR was $2.24 \pm 0.17 \mathrm{ml} / \mathrm{kg} \cdot \min$ in cirrhotics compared to $3.30 \pm 0.23$ $\mathrm{ml} / \mathrm{kg}$ per min in controls $(P<0.005)$. In both groups glucose MCR remained significantly higher than in the basal state until +240 min and was not different between the two groups during the last hour (Fig. 4).

Serum NEFA and blood intermediary metabolite concentrations. Serum NEFA concentrations were higher in cirrhotics than in controls, both fasting ( $1,059 \pm 119$ vs. $686 \pm 109 \mu \mathrm{mol} /$ liter, $P<0.05)$ and during the first $30 \mathrm{~min}$ after oral glucose (Fig. 5) but then fell to similar low levels. Fasting blood lactate concentrations were similar in cirrhotics $(744 \pm 43 \mu \mathrm{mol} / 1)$ and controls $(757 \pm 147 \mu \mathrm{mol} / 1)$, but mean levels were significantly higher in cirrhotics over the $4 \mathrm{~h}$ after the glucose load $(1,136 \pm 54$ vs. $790 \pm 61 \mu \mathrm{mol} /$ liter, $P<0.001$ ) (Fig. 5$)$. In both groups, blood pyruvate concentrations followed a similar pattern to blood lactate levels (data not shown).

Substrate oxidation rates and energy expenditure. After an overnight fast, the rate of carbohydrate oxidation was not signif-
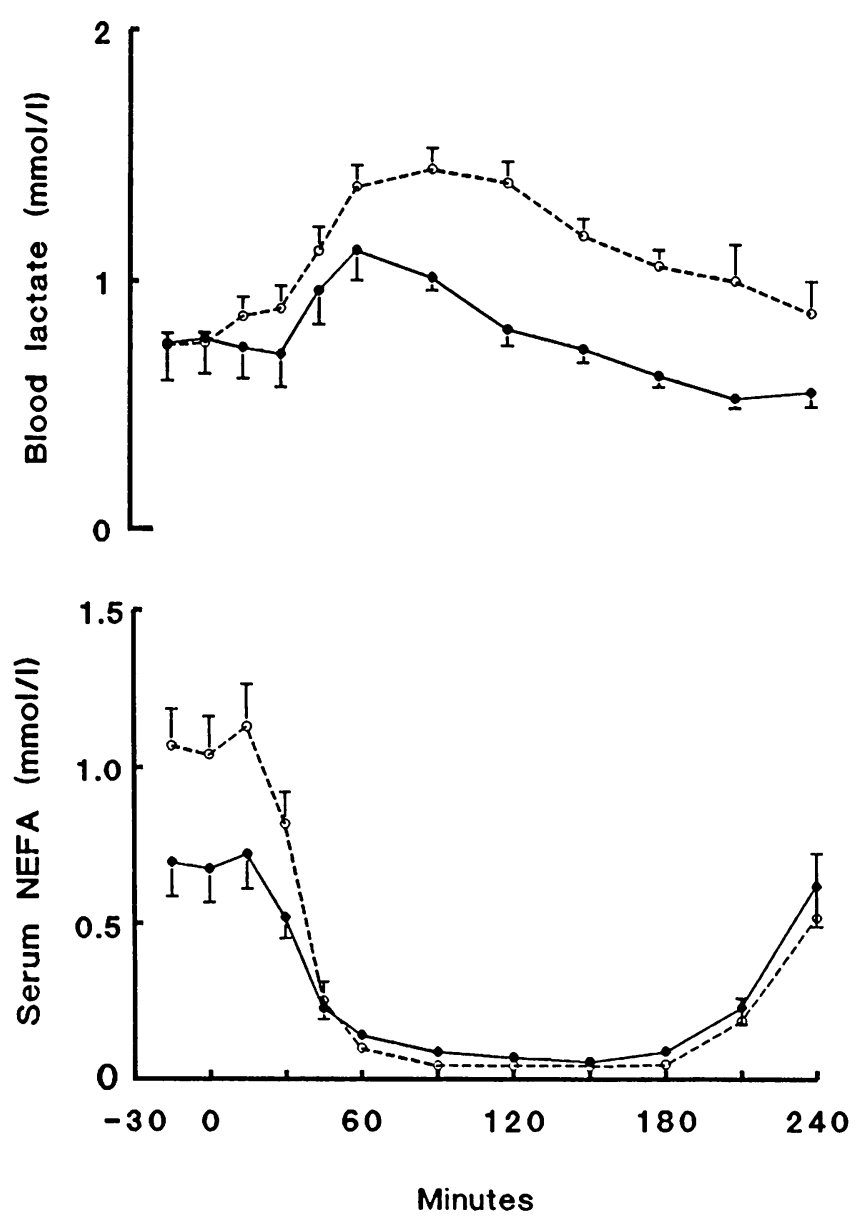

Figure 5. Blood lactate concentrations and serum NEFA levels in eight cirrhotics $(0)$ and eight normal controls $(\bullet)$ after an overnight fast and after ingestion of a $75-\mathrm{g}$ glucose load at $t=0 \mathrm{~min}$. Mean \pm SEM. 
Table II. Rates of Whole-Body Glucose Disposal (Rd), Glucose Oxidation, and Nonoxidative Glucose Disposal in the Basal State and during the $4 \mathrm{~h}$ after a 75-g Oral Glucose Load in Cirrhotic Patients and Normal Control Subjects

\begin{tabular}{lcc}
\hline & $\begin{array}{c}\text { Controls } \\
(n=8)\end{array}$ & $\begin{array}{c}\text { Cirrhotics } \\
(n=8)\end{array}$ \\
\hline Basal & & \\
$\quad$ Glucose Rd $(g / h)$ & $10.25 \pm 0.50$ & $9.06 \pm 1.31$ \\
$\quad \begin{array}{l}\text { Glucose oxidation }(g / h) \\
\text { Percent of total glucose } \\
\quad \text { Rd oxidized }(\%)\end{array}$ & $7.22 \pm 1.28$ & $4.94 \pm 0.79$ \\
$\quad \begin{array}{l}\text { Nonoxidative glucose } \\
\text { Rd }(g / h)\end{array}$ & $69 \pm 11$ & $60 \pm 11$ \\
$\begin{array}{l}\text { After oral glucose } \\
\text { Glucose Rd }(g / h)\end{array}$ & $3.03 \pm 1.12$ & $4.12 \pm 1.19$ \\
$\begin{array}{l}\text { Glucose oxidation }(g / h) \\
\text { Percent of total glucose } \\
\quad \text { Rd oxidized }(\%)\end{array}$ & $19.29 \pm 0.55$ & $18.11 \pm 0.96$ \\
$\quad \begin{array}{l}\text { Nonoxidative glucose } \\
\text { Rd }(g / h)\end{array}$ & $63 \pm 4$ & $12.74 \pm 0.92$ \\
& $7.17 \pm 0.83$ & $72 \pm 7$ \\
\hline
\end{tabular}

Mean \pm SEM.

icantly different in cirrhotics $(82.4 \pm 13.2 \mathrm{mg} / \mathrm{min})$ and controls $(120.4 \pm 21.4 \mathrm{mg} / \mathrm{min})$, but inter-individual variation was high in both groups. The proportion of total basal glucose $\mathbf{R d}$ metabolized via oxidative and nonoxidative pathways did not differ between the two groups ( Table II). Basal lipid oxidation (cirrhotics $65.6 \pm 7.2 \mathrm{mg} / \mathrm{min}$, controls $48.2 \pm 8.3 \mathrm{mg} / \mathrm{min}$; NS) and basal protein oxidation (cirrhotics $1.63 \pm 0.14 \mathrm{~g} / \mathrm{h}$ vs. controls $2.22 \pm 0.28 \mathrm{~g} / \mathrm{h}$; NS) were also not significantly different. Resting energy expenditure after an overnight fast was identical in the two groups (Table III).

After glucose ingestion, lipid oxidation was suppressed in both groups (Fig. 6). The temporal pattern of whole-body lipid oxidation paralleled that of serum NEFA levels (Fig. 4). The total quantity of lipid oxidized during the $4 \mathrm{~h}$ after the glucose load was similar (cirrhotics $7.55 \pm 1.86 \mathrm{~g} / 4 \mathrm{~h}$, controls $7.66 \pm 1.44 \mathrm{~g} / 4 \mathrm{~h}$ ). In both groups glucose oxidation increased after glucose ingestion, concomitantly with the fall in lipid oxidation (Table II, Fig. 6). The total amount of glucose oxidized during the $4 \mathrm{~h}$ after glucose ingestion was similar in cirrhotics $(50.9 \pm 3.7 \mathrm{~g} / 4 \mathrm{~h})$ and controls $(48.4 \pm 2.7 \mathrm{~g} / 4 \mathrm{~h})$, and glucose oxidation rates did not differ significantly at any time point (Fig. 6). In both groups glucose oxidation accounted for approximately two-thirds of total glucose $\mathrm{Rd}$ after glucose inges-

Table III. Resting Energy Expenditure after an Overnight Fast and during the $4 \mathrm{~h}$ after Ingestion of $75 \mathrm{~g}$ of Glucose

\begin{tabular}{lcc}
\hline Energy expenditure & $\begin{array}{c}\text { Controls } \\
(n=8)\end{array}$ & $\begin{array}{c}\text { Cirrhotics } \\
(n=8)\end{array}$ \\
\hline Basal $(\mathrm{kcal} / \mathrm{min})$ & $1.12 \pm 0.07$ & $1.09 \pm 0.07$ \\
Post oral glucose & & \\
$\quad(k \mathrm{cal} / \mathrm{min})$ & $1.20 \pm 0.08$ & $1.17 \pm 0.07$ \\
Incremental $(\%)$ & $7.19 \pm 1.23$ & $8.22 \pm 1.16$
\end{tabular}

Mean \pm SEM.
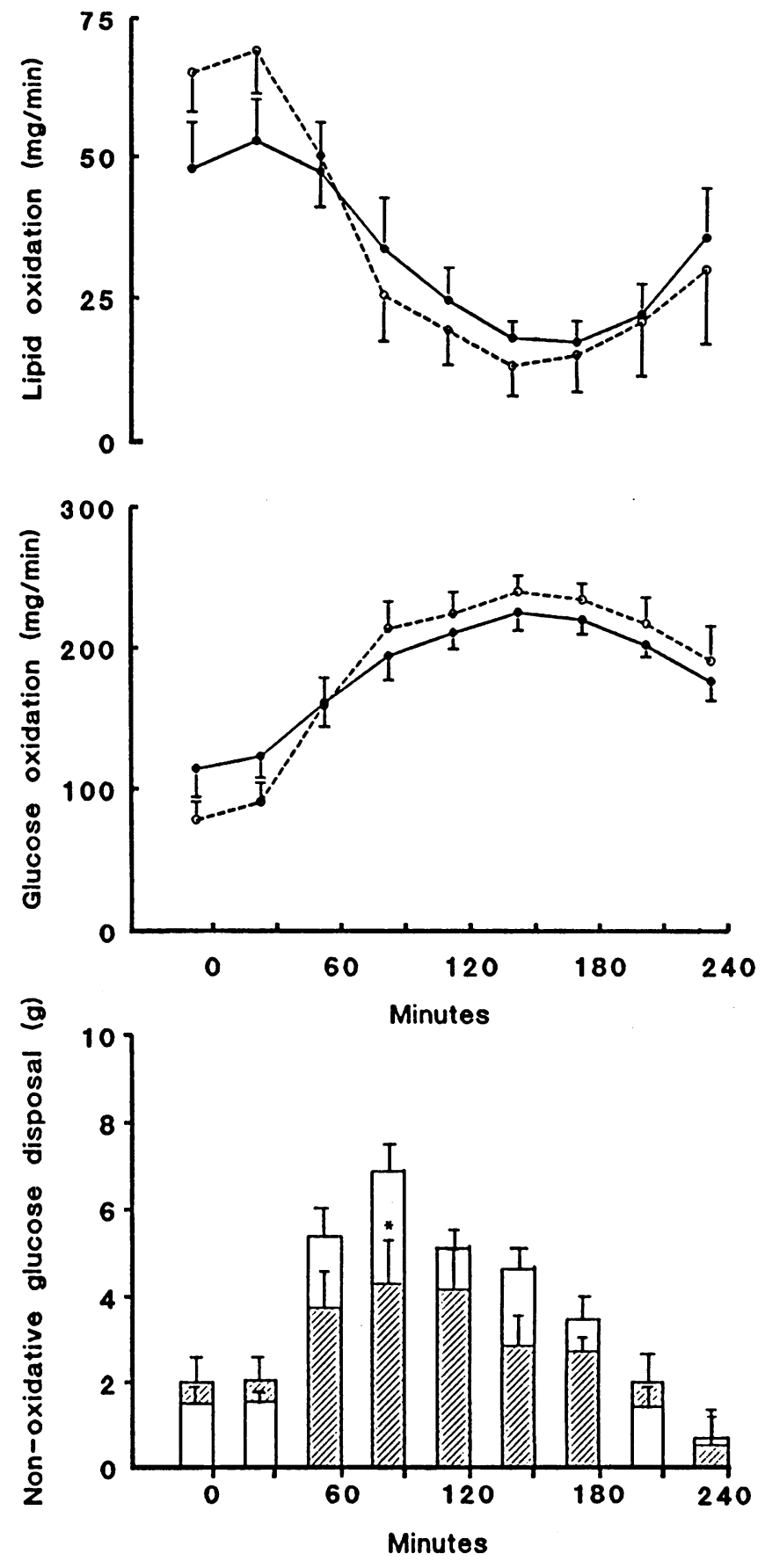

Figure 6. (Top) Rates of whole-body lipid and glucose oxidation in eight cirrhotics $(0)$ and eight normal controls $(\bullet)$ after an overnight fast and after ingestion of a 75-g glucose load at $t=0 \mathrm{~min}$. (Bottom) Nonoxidative glucose disposal in eight cirrhotics $\square$ and eight normal controls $\square$ before and after glucose ingestion. Mean \pm SEM. ${ }^{*} P<0.05$ compared to normal controls.

tion (Table II). The increase in energy expenditure after the glucose load was identical in cirrhotics and controls ( Table III).

Nonoxidative glucose disposal, calculated by subtracting whole-body glucose oxidation and urine glucose excretion from glucose Rd, was similar after an overnight fast (Table II, Fig. 6). In both groups, nonoxidative glucose disposal increased after glucose ingestion. It was significantly lower in 
cirrhotics than controls (Fig. 6, bottom, $P<0.05$ ) during the interval 75-90 min corresponding to the maximal divergence of the plasma glucose curves. However, the reduction in nonoxidative glucose disposal calculated for the entire 4-h period did not reach statistical significance ( cirrhotics 21.1 \pm 5.4 , controls $28.7 \pm 3.3 \mathrm{~g} / 4 \mathrm{~h}$; NS). The incremental nonoxidative glucose disposal after glucose ingestion was lower in cirrhotics than controls $(5.4 \pm 2.3$ vs. $16.7 \pm 4.7 \mathrm{~g} / 4 \mathrm{~h}: P<0.05)$.

\section{Discussion}

The pathophysiological changes underlying the oral glucose intolerance of cirrhosis have not been clearly defined. The rate of change of the plasma glucose concentration is determined by the difference between the rate of entry into the glucose space ( $\mathrm{Ra}$ ) and the rate of disappearance ( $\mathrm{Rd})$. Ra depends on the rate of glucose absorption into portal blood, the amount of absorbed glucose that escapes first-pass hepatic uptake, and the rate of glucose release from the liver. $\mathrm{Rd}$ includes glucose lost into liver and peripheral tissues, but only from the systemic circulation (thus excluding absorbed glucose removed on first passage through the liver ). Rd depends on the timing and magnitude of the insulin secretory response, the insulin sensitivity of the tissues, and on the plasma glucose concentration. We recently showed that insulin insensitivity of peripheral tissues, and a relative impairment of insulin secretion in response to oral glucose, are both factors in the oral glucose intolerance of cirrhosis (13). They would cause glucose intolerance even if there were no difference in the amount of glucose appearing in the systemic circulation.

In the current study we used a dual-isotope technique to determine whether, in cirrhotics, higher glucose levels after glucose ingestion are due simply to a lower $\mathrm{Rd}$, or whether there is also more rapid entry of glucose into the systemic circulation (owing to more rapid absorption, to reduced first-pass hepatic uptake of absorbed glucose, or to impaired suppression of hepatic glucose output). Our results suggest that the higher postprandial glucose levels in cirrhotics were due initially to a higher $\mathrm{Ra}$ of ingested glucose $(\mathrm{RaO})$, and subsequently to a lower $\mathrm{Rd}$ than that found in controls.

After an overnight fast our cirrhotics had normal plasma glucose levels. After glucose ingestion their plasma glucose levels were higher than in controls despite a much greater insulin response (Fig. 1). The plasma glucose curves diverged rapidly; both peaked at $60 \mathrm{~min}$ but continued to diverge until $80 \mathrm{~min}$, when they started to converge. While the curves were diverging, [ $R \mathbf{a}-\mathbf{R d}]$ must have been greater in cirrhotics than controls. Inspection of the curves for $\mathrm{Rd}$, and for total $\mathrm{Ra}, \mathrm{RaO}$, and HGO, should therefore indicate whether the higher [ $\mathrm{Ra}$ - Rd] was due primarily to a higher total $\mathrm{Ra}$ or to a lower $\mathrm{Rd}$.

During the first 20 min after glucose ingestion, total $\mathrm{Ra}$ and $\mathrm{RaO}$ were significantly higher in cirrhotics than in controls; the fall in HGO was similar in the two groups, and there was little change in Rd, which accords with the known delay in the action of insulin on peripheral tissues $(36,37)$. Thus the greater initial increase in plasma glucose in the cirrhotics was accounted for by the sudden rise in $\mathrm{RaO}$. From the difference in plasma glucose concentration and the estimated distribution volume, it can be estimated that $\sim 1.5 \mathrm{~g}$ of extra glucose must have been added to the glucose space to explain the higher plasma level in cirrhotics at $20 \mathrm{~min}$; the net difference in the integrated $\mathrm{RaO}$ during the first $20 \mathrm{~min}$ was $1.82 \mathrm{~g}$ (cirrhotics $5.85 \pm 0.69 \mathrm{~g}$, controls $4.03 \pm 0.30 \mathrm{~g}$ in $20 \mathrm{~min}$ ).

The continuing divergence of the plasma glucose curves from 30 to 80 min could not be explained by a higher $\mathrm{Ra}$ in cirrhotics, as both total $\mathrm{Ra}$ and $\mathrm{RaO}$ during this period were similar to those of controls. However, from 30 to $80 \mathrm{~min} \mathrm{Rd}$ was lower in cirrhotics ( $1 P<0.05$ ); a difference of $2.6 \mathrm{~g}$ of glucose was needed in the glucose space to explain the increased plasma glucose in cirrhotics between 30 and $80 \mathrm{~min}$; the net difference in $\mathrm{Rd}$ during this period was $3.4 \mathrm{~g}$. The reduction in $\mathrm{Rd}$ is compatible with their known insulin insensitivity (13-16), which also accounts for their much lower glucose MCR over the first $3 \mathrm{~h}$. The more obvious difference in MCR than in $\mathrm{Rd}$ is due to the higher plasma glucose in cirrhotics because, at any given Rd, MCR is inversely proportional to the plasma glucose level (38). The convergence of the curves between 80 and 130 min was due largely to the more pronounced fall in total $\mathrm{Ra}$ and $\mathrm{RaO}$ in the cirrhotics after their initial peak at $15 \mathrm{~min}$ (Fig. 3). As the glucose transporter on the serosal surface of the intestinal epithelial cells (Glut 2) has a high $K_{\mathrm{m}}$ for glucose $(\sim 17 \mathrm{mM})$ and transports glucose down its concentration gradient (39), it seems possible that a high plasma glucose concentration will slow the rate of transfer of ingested glucose from intestinal epithelial cells into portal blood (40). The higher plasma glucose levels in cirrhotics would then explain the more marked fall in $\mathrm{RaO}$ after its initial peak, and the subsequent fall in glucose levels would explain the secondary rise in $\mathrm{RaO}$. In that Glut 2 is also the main transporter in hepatocytes, the higher glucose levels in cirrhotics might also have contributed to the reduction in HGO and total Ra and hence to the convergence of the glucose curves.

The higher total $\mathrm{Ra}$ and $\mathrm{RaO}$ in the cirrhotics during the first 20 min was unexpected. We had hypothesized that they would show no difference in the amount of oral glucose appearing in the systemic circulation, as first-pass uptake has been considered quantitatively unimportant in normal subjects $(4,12)$, and a portacaval shunt has little effect on oral glucose tolerance (6-9). However, significantly more $\left[1-{ }^{14} \mathrm{C}\right]-$ glucose dpm appeared in plasma in cirrhotics than in controls during this initial period. The higher $\mathrm{RaO}$ in cirrhotics can only be explained if they absorbed glucose more rapidly or if, initially, they had a reduced first-pass hepatic uptake of portal venous glucose.

There is no obvious reason why cirrhotics should have an increased rate of glucose transport across the intestinal mucosa. The function of the intestinal $\mathrm{Na}^{+}$-glucose co-transporter which transfers glucose from the gut lumen into intestinal epithelial cells has been found to be normal (41), and intestinal perfusion studies have shown a normal rate of glucose absorption in cirrhotics (42). Thus more rapid glucose absorption is an unlikely explanation for the higher initial $\mathrm{RaO}$ in our cirrhotics, and it would be surprising if it had been present only for the first $20 \mathrm{~min}$ or so. The more likely explanation is that our original hypothesis was wrong, and that our cirrhotics had a lower first-pass uptake of glucose than controls. Curiously, however, the results over the entire 4-h period appear to support our original hypothesis. Not only was the overall rate of glucose appearance (from gut plus liver) similar in the two groups, but there was also a remarkable similarity between the $\left[{ }^{14} \mathrm{C}\right.$ ]glucose specific activity curves from 40 to $165 \mathrm{~min}$, indicating a similar admixture of the glucose derived from these two sources. 
Decreased first-pass hepatic uptake of oral glucose would result from the presence in cirrhotics of large collaterals shunting blood directly from the portal system into the systemic circulation, and of smaller intrahepatic shunts connecting portal and hepatic venous tributaries. Hepatic glucose uptake might also be impaired if there is a reduced functioning hepatocyte mass and/or capillarization of hepatic sinusoids (43), which might be expected to slow the rate of glucose exchange between hepatocytes and sinusoidal blood. Maintenance of normal basal rates of HGO (Fig. 3 ) from a reduced number of hepatocytes, or in the presence of capillarization, might require a greater hepatocyte-sinusoidal glucose gradient; if basal hepatocyte glucose concentrations are raised in cirrhotics, then after glucose ingestion there would be a delay (compared to controls) before this gradient was reversed to allow net hepatic glucose uptake.

Why does first-pass hepatic uptake appear important initially, but not later after glucose ingestion? In normal humans the hepatic total glucose extraction ratio (total amount in minus total amount out per total amount in) must also define the proportion of absorbed glucose removed on first passage; this is also true for glucose passing through the liver in cirrhotics, but in the presence of large portal-systemic shunts the extraction ratio from portal venous blood must be lower than the hepatic extraction ratio. Ferrannini et al. (12), using intravenous $\left[{ }^{3} \mathrm{H}\right]$ glucose infusion and hepatic venous catheterization in normal subjects, found a splanchnic extraction ratio for recirculating $\left[{ }^{3} \mathrm{H}\right]$ glucose of $\sim 2.7 \%$ in the basal state, and little change in the ratio over $3.5 \mathrm{~h}$ after glucose ingestion. However, the total glucose extraction ratio (oral + recirculating) was significantly greater $(\sim 7.5 \%)$ during the first $30 \mathrm{~min}$ after glucose ingestion, falling subsequently to values similar to those for recirculating glucose alone. The authors emphasized that this was a minimal estimate for the total glucose extraction ratio because, in order to calculate total hepatic glucose input, they used the rate at which ingested glucose appeared in the systemic circulation and not the true but unmeasurable rate of its absorption into the portal venous blood.

These results explain why first pass uptake of ingested glucose has been considered to be quantitatively unimportant in the overall disposal of an oral glucose load. They are clearly relevant to our findings in cirrhotics, and to earlier findings in patients with portacaval shunts $(8,9)$. If, throughout the period after glucose ingestion, the extraction ratio was only $2-3 \%$ it would be difficult to detect first-pass uptake in controls from measurements made on systemic blood; consequently one would be unable to demonstrate, in patients with portal-systemic shunting, that significantly more ingested glucose had appeared in the systemic circulation (e.g., 99\% vs. 97\%) - even if the patients had an end-to-side portacaval shunt.

Insulin appears to play a permissive role in promoting hepatic glucose uptake. The main determinant of glucose transport into and out of the liver is the glucose concentration gradient between sinusoids and hepatocytes (3). Before glucose ingestion there is net glucose output, and the glucose concentration in hepatocytes is higher than that in the sinusoids (44). Net glucose uptake will occur when the sinusoidal glucose concentration rises above that in the hepatocyte. Ferrannini et al. (12) found that net splanchnic glucose uptake, like the total glucose extraction ratio, was at its highest during the first 30 min after oral glucose (12). This high glucose uptake suggests that in our study the glucose gradient between sinusoids and hepatocytes would be at a maximum during the first $30 \mathrm{~min}$; it may fall subsequently due to an increased glucose concentration within hepatocytes. The enrichment of sinusoidal blood with ingested glucose would also be maximal in the first $30 \mathrm{~min}$ because, while the arterial glucose level was still relatively low the glucose absorption rate was at its highest during this period (Fig. 3). The combination of a high net uptake of sinusoidal glucose and its enrichment with absorbed glucose would cause a disproportionate increase in the absolute amount of ingested glucose taken up by the liver on first pass in controls. We believe that this allowed us to find a significantly greater initial $\mathrm{RaO}$ in our cirrhotics. Later in our study the arterial glucose rose and $\mathrm{RaO}$ fell; this would have led to a relative enrichment of sinusoidal blood with recirculating glucose which, together with a fall in net glucose uptake after $30 \mathrm{~min}$ (12), would have caused a marked fall in the amount of absorbed glucose removed on first pass. This would explain the similarity of the overall $\mathrm{RaO}$ (i.e., over $4 \mathrm{~h}$ ) in our two groups.

In both groups $\left[1-{ }^{14} \mathrm{C}\right]$ glucose was still appearing in the systemic circulation at $240 \mathrm{~min}$ (at $\sim 1.8 \mathrm{mg} / \mathrm{kg} / \mathrm{min}$ of glucose; Fig. 3), suggesting incomplete absorption of the glucose load. Studies in humans (45) and in dogs (46) have estimated that only $80-85 \%$ of an oral glucose load is absorbed within $4 \mathrm{~h}$. Assuming that $80-85 \%$ of the oral glucose load was absorbed during the period of our study, it can be estimated that the total amount of ingested glucose removed by first pass hepatic uptake over $4 \mathrm{~h}$ was $6.2-9.9 \mathrm{~g}(8.3-13.2 \%$ of glucose ingested $)$ in the cirrhotics and 5.8-9.6 $\mathrm{g}(7.7-12.8 \%$ of glucose ingested $)$ in the controls. These estimates are similar to those of other investigators $(4,12,22)$ and are likely to be maximal estimates, as some glucose may be utilized directly by the intestine during absorption.

Measurement of glucose Ra using [ ${ }^{3} \mathrm{H}$ ] glucose is bedevilled by methodological problems, attributed to a slowly eliminated nonglucose metabolite (47), an isotope effect (48-50), and/or the use of noncompartmental analysis in a non-steady state $(49,51)$. These may have affected our absolute estimates of total Ra and HGO; the relatively slow changes in glucose $\mathrm{Rd}$, and the absence of negative estimates of HGO, however, suggest the error is not large. Furthermore, there is no obvious reason why the error inherent in the measurement of glucose Ra should differ between cirrhotics and controls; comparisons between patient and control groups should therefore remain valid. For $\left[{ }^{14} \mathrm{C}\right]$ glucose these problems do not appear to arise, and compartmental effects will be minimized if there is a constant ratio of absorption of the isotope and native glucose from the gut.

Overall HGO during the $4 \mathrm{~h}$ after glucose ingestion was, like basal glucose turnover, slightly but not significantly lower in cirrhotics $(17.8 \pm 4.8 \mathrm{~g})$ than in controls $(21.9 \pm 3.9 \mathrm{~g})$; inasmuch as the rate of fall of HGO was similar in the two groups (Fig. 3), failure of suppression of HGO could not have contributed to the impairment of oral glucose tolerance. By contrast both type 2 (52) and poorly controlled insulin-deprived type 1 diabetics (53) show a reduced suppression of HGO after glucose ingestion; in type 2 diabetes this is due to a combination of decreased insulin secretion and hepatic insensitivity to insulin (52). Unlike type 2 diabetics, cirrhotics have markedly increased insulin levels, both fasting and after oral glucose (Fig. 1), owing to increased secretion and decreased clearance of insulin (13). Hepatic sensitivity to insulin is difficult to assess in cirrhosis, as portal-systemic shunting and architectural dis- 
tortion affect both the delivery of insulin to the liver and its distribution within it. Hepatic insensitivity to insulin might have been present in our patients as their basal glucose turnover was normal, despite serum insulin levels that were six times higher than in controls.

Glucose uptake by tissues other than brain rises in proportion to the plasma glucose concentration (39). Using Bergman's "minimal model" of insulin and glucose dynamics after an intravenous glucose bolus, we have shown that the ability of hyperglycemia per se to promote glucose disposal is normal in cirrhotics with normal fasting blood glucose levels (54), and insulin insensitive cirrhotics have normal rates of glucose utilization during a hyperglycemic clamp $(13,55)$. The rise in glucose MCR after oral glucose reflects the enhancing effect of insulin on glucose uptake, and is largely independent of glucose levels within the physiological range. In keeping with their marked decrease in whole-body insulin sensitivity (13-16), our cirrhotics had a lower glucose MCR over the $4 \mathrm{~h}$ after oral glucose $(P<0.05$; Fig. 4$)$ despite insulin levels that were four to six times higher than in controls. Furthermore, although the timing of the insulin response was similar in the two groups (maximum levels occurring at 50-60 min, Fig. 1), the rise in glucose MCR after glucose ingestion was much slower in the cirrhotics (Fig. 4 ) suggesting that, in addition to insulin insensitivity, an abnormality of insulin delivery to the effector compartment may play an important role in oral glucose intolerance. A similar delay in the onset of action of insulin was found in cirrhotics during an euglycemic clamp $(13,14)$.

Uptake of glucose by insulin-sensitive tissues is influenced by the availability of lipid fuels (56). Our cirrhotics had increased basal serum NEFA levels (Fig. 5), and basal lipid oxidation rates tended to be higher in our cirrhotics, with a reciprocal decrease in the rates of carbohydrate oxidation (Fig. 6). Others found that overnight fasted cirrhotics derive more energy from the oxidation of lipid than matched normal subjects $(57,58)$. In view of the small number of subjects studied, and the quantitatively minor contribution of insulin sensitive tissues to overall glucose disposal in the basal state $(59,60)$, our failure to find a significant difference in the basal lipid or carbohydrate oxidation rate may represent a type 2 statistical error. After glucose ingestion serum NEFA levels fell to similar low levels, with a concomitant decrease in lipid oxidation. Much of the enhanced glucose utilisation after oral glucose therefore represents glucose oxidized to provide energy that in the basal state was provided by lipid oxidation. Additional energy is needed to support synthetic processes such as glycogen and fat storage. Indeed, in our control subjects $55 \%$ of the increased glucose uptake after oral glucose was accounted for by an increase in glucose oxidation. Although glucose oxidation after glucose ingestion was similar in both groups ( Table II), in cirrhotics $88 \%$ of the suprabasal glucose utilization was accounted for by the increase in glucose oxidation as their basal rate tended to be lower. Nevertheless, the proportion of glucose oxidized after the oral load was similar in the cirrhotics $(72 \%)$ and controls (63\%).

After glucose ingestion lactate and pyruvate levels were higher in the cirrhotics. Because HGO and glucose carbon recycling were similar to those of controls, we believe that increased production, rather than decreased hepatic clearance, is the more likely explanation for the higher lactate levels. Skeletal muscle is an unlikely source of this lactate as muscle lactate release decreases after glucose ingestion $(21,22)$. The most likely explanation is that the higher plasma glucose levels in cirrhotics after glucose ingestion result in higher rates of nonoxidative glycolysis in tissues other than muscle (61). Nonoxidative glucose disposal includes, in addition to glucose stored as glycogen, glucose metabolized via glycolysis to lactate and pyruvate, and glucose that may be converted to triglyceride. Thus, although the reduction in nonoxidative glucose disposal in cirrhotics was not statistically significant $(21 \pm 5$ vs. $29 \pm 3$ $\mathrm{g} / 4 \mathrm{~h}$ ), and it formed a similar proportion of total glucose disposal ( $28 \pm 6 \%$ vs. $37 \pm 4 \%$ ), the lactate data (suggesting increased glycolytic flux in cirrhosis) could mean lower muscle glycogen deposition. Impaired muscle glycogen deposition in cirrhosis has been found under euglycemic clamp conditions and is associated with impaired activation of muscle glycogen synthase by insulin (14). The mass action effect of glucose might be expected to overcome any impairment of muscle glucose transport, but unless intracellular glucose-6-phosphate levels are increased above those in controls hyperglycemia cannot compensate for a defect in muscle glycogen synthase activation by insulin (62). It can be estimated that suprabasal nonoxidative glucose disposal in the normal subjects was only $\sim 16 \mathrm{~g}$. Thus, while our data would be compatible with an impairment of tissue glycogen deposition after oral glucose, in quantitative terms glucose storage as glycogen must play a small part in overall glucose disposal as suggested by earlier reports (22).

Our findings suggest that oral glucose intolerance in cirrhosis is due $(a)$ to an initial decrease in first-pass hepatic uptake of ingested glucose so that more glucose enters the systemic circulation and $(b)$ to insulin insensitivity of peripheral tissues. A delay in the onset of insulin action may also play a role. Hyperglycemia and hypersecretion of insulin (13) are important compensatory mechanisms so that overall glucose $\mathrm{Rd}$ is normal.

\section{Acknowledgments}

The study was supported by the British Diabetic Association.

\section{References}

1. Megyesi, C., E. Samols, and V. Marks. 1967. Glucose tolerance and diabetes in chronic liver disease. Lancet. ii:1051-1056.

2. Conn, H. O., W. Schreiber, and S. G. Elkington. 1971. Cirrhosis and diabetes. II. Association of impaired glucose tolerance with portal-systemic shunting in Laennec's cirrhosis. Dig. Dis. 16:227-239.

3. Kruszynska, Y. T., and N. McIntyre. 1991. Carbohydrate metabolism. In Oxford Textbook of Clinical Hepatology. N. McIntyre, P.-J. Benhamou, J. Bircher, M. Rizzetto, and J. Rodes, editors. Oxford University Press, Oxford, UK. 129-143.

4. Radziuk, J., T. J. McDonald, D. Rubenstein, and J. Dupre. 1978. Initial splanchnic extraction of ingested glucose in normal man. Metab. Clin. Exp. 27:657-679.

5. McIntyre, N., D. S. Turner, and C. D. Holdsworth. 1970. The role of the portal circulation in glucose and fructose tolerance. Diabetologia. 6:593-596.

6. Assal, J-P, R. Levrat, W. Stauffacher, and A. E. Renold. 1971. Metabolic consequences of portacaval shunting in the rat: effects on glucose tolerance and serum immunoreactive insulin response. Metab. Clin. Exp. 20:850-858.

7. Waddell, W. R., and K. E. Sussman. 1967. Plasma insulin after diversion of portal and pancreatic venous blood to vena cava. J. Appl. Physiol. 22:808-812.

8. Smith-Laing, G., S. Sherlock, and O. K. Faber. 1979. Effects of spontaneous portal-systemic shunting on insulin metabolism. Gastroenterology. 76:685690.

9. Holdsworth, C. D., L. Nye, and E. King. 1972. The effect of portacaval anastomosis on oral carbohydrate tolerance and on plasma insulin levels. Gut. 13:58-63.

10. Felig, P., J. Wahren, and R. Hendler. 1975. Influence of oral glucose ingestion on splanchnic glucose and gluconeogenic substrate metabolism in man. Diabetes. 24:468-475.

11. Katz, L. D., M. G. Glickman, S. Rapopart, E. Ferrannini, and R. A. DeFronzo. 1983. Splanchnic and peripheral disposal of oral glucose in man. Diabetes. 32:675-679. 
12. Ferrannini, E., O. Bjorkman, G. A. Reichard, A. Pilo, M. Olsson, J. Wahren, and R. A. DeFronzo. 1985. The disposal of an oral glucose load in healthy subjects: a quantitative study. Diabetes. 34:580-588.

13. Kruszynska, Y. T., P. D. Home, and N. McIntyre. 1991. The relationship between insulin sensitivity, insulin secretion and glucose tolerance in cirrhosis. Hepatology. 14:103-111.

14. Kruszynska, Y. T., N. Williams, M. Perry, and P. D. Home. 1988. The relationship between insulin sensitivity and skeletal muscle enzyme activities in hepatic cirrhosis. Hepatology. 8:1615-1619.

15. Proietto, J., F. P. Alford, and F. J. Dudley. 1980. The mechanism of the carbohydrate intolerance in cirrhosis. J. Clin. Endocrinol. Metab. 51:1030-1036.

16. Taylor, R., R. J. Heine, J. Collins, O. F. W. James, and K. G. M. M. Alberti. 1985. Insulin action in cirrhosis. Hepatology. 5:64-71.

17. Perez, G., B. Trimarco, B. Ungaro, F. Rengo, and L. Sacca. 1978. Glucoregulatory response to insulin-induced hypoglycaemia in Laennec's cirrhosis. $J$. Clin. Endocrinol. Metab. 46:778-783.

18. Piniewska, D. M., A. J. McCulloch, M. G. Bramble, R. Taylor, C. O. Record, and K. G. M. M. Alberti. 1986. Glucose turnover in compensated hepatic cirrhosis. Horm. Metab. Res. 18:834-837.

19. Petrides, A. S., and R. A. DeFronzo. 1989. Glucose and insulin metabolism in cirrhosis. J. Hepatol. 8:107-114.

20. Leatherdale, B. A., R. A. Chase, J. Rogers, K. G. M. M. Alberti, P. Davies, and C. O. Record. 1980. Forearm glucose uptake in cirrhosis and its relationship to glucose tolerance. Clin. Sci. 59:191-198.

21. Jackson, R. A., R. D. Roshania, M. I. Hawa, B. M. Sim, and L. DiSilvio. 1986. Impact of glucose ingestion on hepatic and peripheral glucose metabolism in man: an analysis based on simultaneous use of the forearm and double isotope techniques. J. Clin. Endocrinol. Metab. 63:541-549.

22. Kelley, D., A. Mitrakou, H. Marsh, F. Schwenk, J. Benn, G. Sonnenberg, M. Arcangeli, T. Aoki, J. Sorensen, M. Berger, et al. 1988. Skeletal muscle glycolysis, oxidation and storage of an oral glucose load. J. Clin. Invest. 81:1563-1571.

23. Ferrannini, E. 1988. The theoretical bases of indirect calorimetry: a review. Metab. Clin. Exp. 37:287-301.

24. Jequier, E., and J.-P. Felber. 1987. Indirect calorimetry. In Techniques for Metabolic Investigation in Man. K. G. M. M. Alberti, P. D. Home, and R. Taylor, editors. Bailliere's Clinics in Endocrinology and Metabolism: Volume 1, Part 1. Bailliere-Tindall, London. 911-935.

25. Frayn, K. N. 1983. Calculation of substrate oxidation rate in vivo from gaseous exchange. J. Appl. Physiol. 55:628-634.

26. Somogyi, M. J. 1945. Determination of blood sugar. J. Biol. Chem. 160:69-73.

27. Bloom, B. 1967. The simultaneous determination of [C14] and [H3] in the terminal groups of glucose. Anal. Biochem. 3:85-87.

28. Reichard, G. A., N. F. Moury, N. J. Hochella, A. L. Patterson, and S. Weinhouse. 1963. Quantitative estimation of the Cori cycle in the human. $J$. Biol. Chem. 238:495-501.

29. Soeldner, J. S., and D. Sloane. 1965. Critical variables in the radioimmunoassay of serum insulin using the double-antibody technique. Diabetes. 14:771779 .

30. Lloyd, B., J. Burrin, P. Smythe, and K. G. M. M. Alberti. 1978. Enzymatic fluorimetric continuous flow assays for blood glucose, lactate, pyruvate, alanine, glycerol and 3-hydroxybutyrate. Clin. Chem. 24:1724-1729.

31. Hawk, P. B. 1947. Kjeldahl method. In Practical Physiological Chemistry, 12th edition, Blakiston, Toronto. 814-822.

32. Steele, R. 1959. Influences of glucose loading and of injected insulin on hepatic glucose output. Ann. N.Y. Acad. Sci. 82:420-430.

33. Wolfe, R. R. 1984. Tracers in Metabolic Research: Radioisotope and Stable Isotope/Mass Spectrometry Methods. Alan R Liss, Inc., New York. 81101.

34. Chiasson, J. L., J. E. Liljenquist, W. W. Lacy, A. S. Jennings, and A. D. Cherrington. 1977. Gluconeogenesis: methodological approaches in vivo. Fed. Proc. 36:229-235.

35. Zar, J. H. 1984. Biostatistical Analysis, 2nd edition. Prentice Hall, Inc., Englewood Cliffs, NJ. 97-121.

36. Sherwin, R. S., K. J. Kramer, J. D. Tobin, P. A. Insel, J. E. Liljenquist, M. Berman, and R. Andres. 1974. A model of the kinetics of insulin in man. J. Clin. Invest. 53:1481-1492.

37. Prager, R., P. Wallace, and J. M. Olefsky. 1986. In vivo kinetics of insulin action on peripheral glucose disposal and hepatic glucose output in normal and obese subjects. J. Clin. Invest. 78:472-481.

38. Gottesman, I., L. Mandarino, and J. Gerich. 1984. Use of glucose uptake and glucose clearance for the evaluation of insulin action in vivo. Diabetes. 33:184-192.

39. Mueckler, M. 1990. Family of glucose-transporter genes: implications for glucose homeostasis and diabetes. Diabetes. 39:6-11.

40. Mokuda, O., Y. Sakamoto, T. Ikeda, and H. Mashiba. 1989. Direct inhibi- tory effect of high glucose in mesenteric artery on glucose absorption from isolated perfused rat intestine. Ann. Nutr. Metab. 33:330-332.

41. Duclos, B., P. Bories, J. C. Mathieu-Daude, and H. Michel. 1991. Jejunal permeability to water and electrolytes in patients with chronic intrahepatic hypertension: evidence for a role of aldosterone. Gut. 32:640-644.

42. Talley, R. B., H. P. Schedl, and J. A. Clifton. 1964. Small intestinal glucose, electrolyte and water absorption in cirrhosis. Gastroenterology. 47:382387.

43. Schaffner, F. and H. Popper. 1963. Capillarisation of hepatic sinusoids in man. Gastroenterology. 44:239-242.

44. Niewoehner, C. B., and F. Q. Nuttall. 1988. Relationship of hepatic glucose uptake to intrahepatic glucose concentration in fasted rats after glucose load. Diabetes. 37:1559-1566.

45. Bjorkman, O., L. S. Eriksson, B. Nyberg, and J. Wahren. 1990. Gut exchange of glucose and lactate in basal state and after oral glucose ingestion in postoperative patients. Diabetes. 39:747-751

46. Abumrad, N. N., A. D. Cherrington, P. E. Williams, W. W. Lacy, and D. A. Rabin. 1982. Absorption and digestion of a glucose load in the conscious dog. Am. J. Physiol. 242:E398-E406.

47. Neely, R. D. G., D. P. Rooney, A. B. Atkinson, B. Sheridan, C. N. Ennis, E. R. Trimble, and P. M. Bell. 1990. Underestimation of glucose turnover determined using 6-3H glucose tracer in non-steady state. The role of a tritiated tracer impurity. Diabetologia. 33:681-687.

48. Argoud, G., D. S. Schade, and R. P. Eaton. 1987. Underestimation of hepatic glucose production by radioactive and stable tracers. Am. J. Physiol. 252:E606-E615.

49. Finegood, D., R. N. Bergman, and M. Vranic. 1988. Modelling error and apparent isotope discrimination confound estimation of endogenous glucose production during euglycaemic glucose clamps. Diabetes. 37:1025-1034.

50. Bell, P. M., R. G. Firth, and R. A. Rizza. 1986. Assessment of insulin action in insulin-dependent diabetes mellitus using $6-{ }^{14} \mathrm{C}$-glucose, $3-{ }^{3} \mathrm{H}$-glucose, and $2-{ }^{3} \mathrm{H}$-glucose: differences in the apparent pattern of insulin resistance depending on the isotope used. J. Clin. Invest. 78:1479-1486.

51. Cobelli, C., A. Mari, and E. Ferrannini. 1987. Non-steady state: error analysis of Steele's model and developments for glucose kinetics. Am. J. Physiol. 252:E679-E689.

52. Firth, R. G., P. M. Bell, H. M. Marsh, I. Hansen, and R. A. Rizza. 1986. Postprandial hyperglycaemia in patients with non-insulin-dependent diabetes mellitus: role of hepatic and extrahepatic tissues. J. Clin. Invest. 77:1525-1532.

53. Pehling, G., P. Tessari, J. E. Gerich, M. W. Haymond, F. J. Service, and R. A. Rizza. 1984. Abnormal meal carbohydrate disposition in insulin-dependent diabetes: relative contributions of endogenous glucose production and initial splanchnic uptake and effect of intensive insulin therapy. J. Clin. Invest. 74:985991.

54. Kruszynska, Y. T., and N. McIntyre. 1991. Assessment of glucose effectiveness and insulin sensitivity in cirrhosis by the "minimal model". Hepatology. 14:231 A (Abstr.)

55. Vetter, D., S. Fratte, P. Winiszewski, M. Reville, E. Hirsch, F. Roze, J. F. Blickle, M. Pinget, M. Doffoel, and R. Bockel. 1990. Consequences de l'hyperglycemie sur le metabolisme glucidique et azote dans la cirrhose: exploration par une epreuve de clamp hyperglycemique. Gastroenterol. Clin. Biol. 14:483-491.

56. Randle, P. J., C. N. Hales, P. B. Garland, and E. A. Newsholme. 1963. The glucose fatty acid cycle. Its role in insulin insensitivity and the metabolic disorders of diabetes mellitus. Lancet 1:785-789.

57. Owen, O. E., V. E. Trapp, G. A. Reichard, M. A. Mozzoli, J. Moctezuma, P. Paul, C. L. Skutches, and G. Boden. 1983. Nature and quantity of fuels consumed in patients with alcoholic cirrhosis. J. Clin. Invest. 72:1821-1832.

58. Merli, M., O. Riggio, A. Romiti, F. Ariosto, L. Mango, G. Pinto, M. Savioli, and L. Capocaccia. 1990. Basal energy production rate and substrate use in stable cirrhotic patients. Hepatology. 12:106-112.

59. Cahill, G. F., and O. E. Owen. 1968. Some observations on carbohydrate metabolism in man. In Carbohydrate Metabolism and its Disorders. F. Dickens, P. J. Randle, and W. J. Whelan, editors. Academic Press, Inc., New York. 497522.

60. Andres, R., G. Cader, and K. L. Zierler. 1956. The quantitatively minor role of carbohydrate in oxidative metabolism by skeletal muscle in intact man in the basal state: measurements of oxygen and glucose uptake and carbon dioxide and lactate production in the forearm. J. Clin. Invest. 35:671-682.

61. Yki-Jarvinen, H., C. Bogardus, and J. E. Foley. 1990. The rate of glucose disposal in extramuscular tissues: the key regulator of plasma lactate concentrations in resting human subjects. Metab. Clin. Exp. 39:859-864.

62. Yki-Jarvinen, H., D. Mott, A. A. Young, K. Stone, and C. Bogardus. 1987. Regulation of glycogen synthase and phosphorylase activities by glucose, insulin and basal enzyme activity in human skeletal muscle. J. Clin. Invest. 80:95-100. 